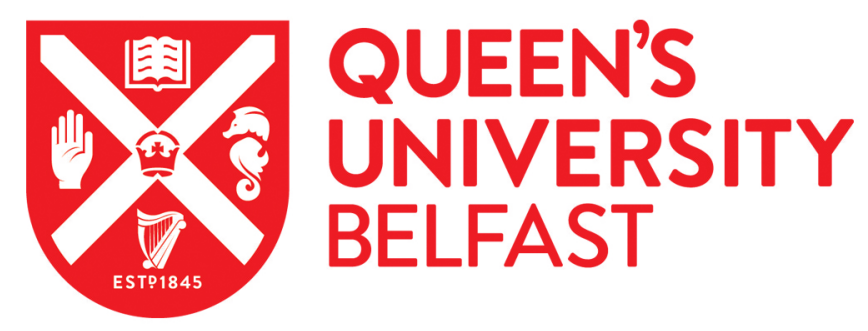

\title{
Heavy Metal (PTE) Ecotoxicology, Data Review: Traditional vs. a Compositional Approach
}

\author{
Mullineaux, S. T., McKinley, J., Marks, N., Scantlebury, M., \& Doherty, R. (2021). Heavy Metal (PTE) \\ Ecotoxicology, Data Review: Traditional vs. a Compositional Approach. Science of the Total Environment, \\ [145246]. https://doi.org/10.1016/j.scitotenv.2021.145246
}

\section{Published in:}

Science of the Total Environment

\section{Document Version:}

Peer reviewed version

Queen's University Belfast - Research Portal:

Link to publication record in Queen's University Belfast Research Portal

\section{Publisher rights}

C) 2021 Elsevier B.V.

This manuscript version is made available under the CC-BY-NC-ND 4.0 license http://creativecommons.org/licenses/by-nc-nd/4.0/,which permits distribution and reproduction for non-commercial purposes, provided the author and source are cited.

\section{General rights}

Copyright for the publications made accessible via the Queen's University Belfast Research Portal is retained by the author(s) and / or other copyright owners and it is a condition of accessing these publications that users recognise and abide by the legal requirements associated with these rights.

Take down policy

The Research Portal is Queen's institutional repository that provides access to Queen's research output. Every effort has been made to ensure that content in the Research Portal does not infringe any person's rights, or applicable UK laws. If you discover content in the Research Portal that you believe breaches copyright or violates any law, please contact openaccess@qub.ac.uk. 
1 Heavy Metal (PTE) Ecotoxicology, Data Review: Traditional vs. a Compositional Approach

2 Authors S. T. Mullineaux, J. M. McKinley, N. J. Marks, D. M. Scantlebury, R. Doherty

3 Corresponding Author: Shay Mullineaux: smullineaux01@qub.ac.uk

4

5

6

7

8

9

10

11

12

13

14 3

Present Address:

School of Biological Sciences, 1-33 Chlorine Gardens, Belfast, BT9 5AJ, United Kingdom of Great

Britain and Northern Ireland

School of Natural and Built Environment, Elmwood Avenue, Belfast, BT7 1NN, United Kingdom of Great Britain and Northern Ireland

School of Natural and Built Environment, David Keir Building, Stranmillis Road, Belfast, BT9 5AG, United Kingdom of Great Britain and Northern Ireland

Highlights

- First ecotoxicological study to compare compositional and "traditional" approaches.

- Both $\log 10$ and clr resolve compositional trends at the point of the individual.

- The clr transformation is best able to resolve trends between PTEs.

- A compositional approach should be adopted for terrestrial ecotoxicology. 
25

26

27

28

29

30

31

32

33

34

35

36

37

38

39

40

41

42

43

44

45

46

47

48

49

50

51

52

53
Centred log ratio vs.

$\log 10$ transformation
Centred log ratio vs.

Untransformed $\log 10$ transformation vs

Untransformed

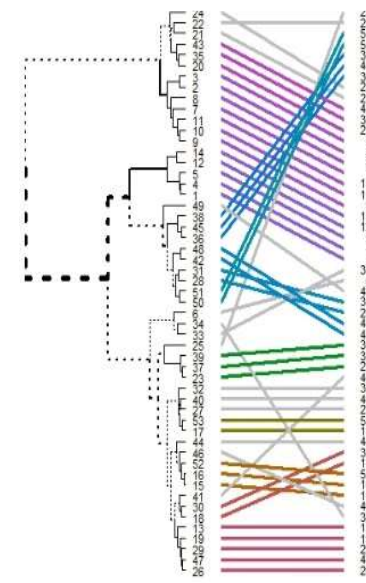

\begin{tabular}{llllllll}
\hline 30 & 25 & 20 & 15 & 1 & 1 & \\
\hline & 20 & 10 & 5 & 0
\end{tabular}
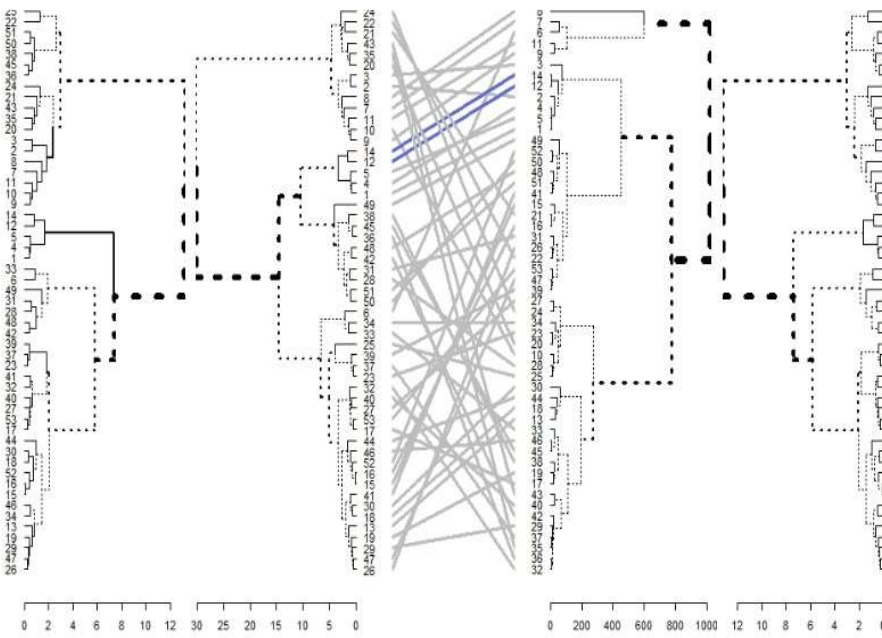

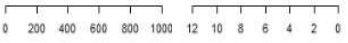

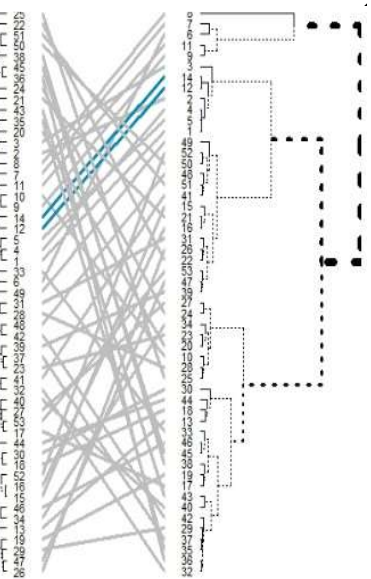

Centred log ratio and the $\log 10$ transformation are the most congruent

Centred log ratio

$\log 10$ transformation

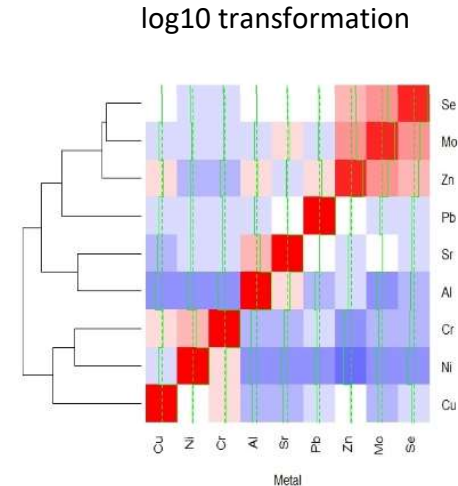

Centred log ratio shows more distinct clusters than the log10 transformation

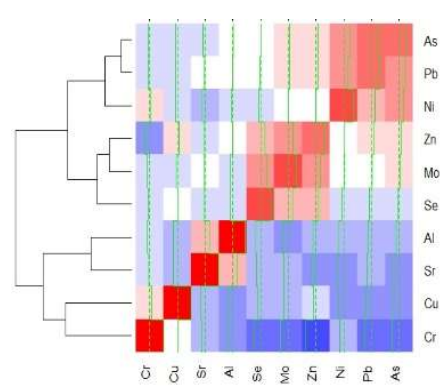

Metal

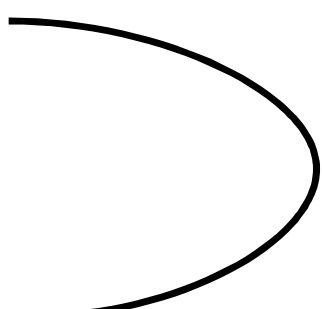

Centred log ratio

log10 transformation
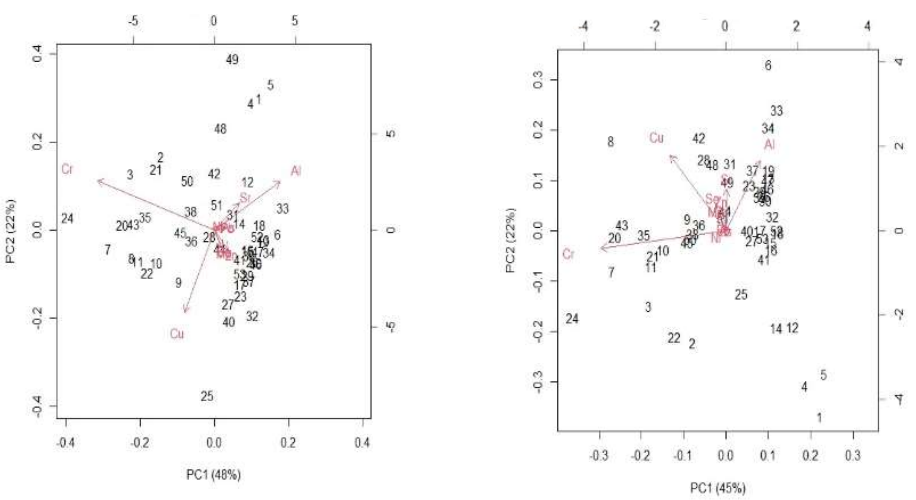

Centred log ratio open-up the data more than the log10 transformation 
Potentially Toxic Elements (PTEs) otherwise known as heavy metals are ubiquitous in soils and can have a range of negative health and environmental impacts. In terrestrial systems understanding how PTEs move in the environment is made challenging by the complex interactions within soil and the wider environment and the compositional nature of PTEs. PTEs are compositional because data of individual PTEs within in a sample are ratios which may be under a sum constraint, where individual components sum up to a whole. In this study three different scenarios were considered, one using the centred log ratio transformation (clr) a compositional transformation, the more "traditional" $\log 10$ transformation (log10) and untransformed data acting as a comparison (unt) were applied to four different datasets. Three were the Liver, Muscle and Kidney tissue of Eurasian Badgers (Meles meles) and the fourth was soil and data were extracted from a regional geospatial survey. Cluster analysis demonstrated that the clr and $\log 10$ transformation were able to resolve compositional trends at the point of the individual sample, while unt could not and did not meet the preconditions for the next phase of analysis. At the level of compositional trends between PTEs complex heatmaps demonstrated that clr was able to isolate PTE relationships and highlight commonalities between different datasets, whilst log10 could not. In the final phase, principal component analysis (PCA) of the clr transformation showed similarities between the signals in the soft tissues and the disparities they had with soil, whilst the log10 transformation was unable to achieve this. Overall, the clr transformation was shown to perform more consistently under a variety of analytical scenarios and the compositional approach will provide more realistic interpretations about PTEs in both soil and animal soft tissue than the $\log 10$ or unt conditions. 
1. Introduction

Contamination is defined as a substance being active in a system where it does not naturally occur or being present above previously recorded background levels, whilst pollution is contamination that can lead to ill effects in living organisms, whether they be human or another species (Chapman, 2007). In the Geosciences, questions of contaminants and potential pollution are encountered often and analysing their effects and movement in the environment is essential. However, a complication faced by many analysts is that many data sets used in analyses are compositional in nature, where compositional data are defined as multiple positive vectors being part of a whole or unit sum constraint (Aitchison, 1994). These compositions are formed from separate balances and the main rationale of compositional transformations is to reduce the dimensions of the data whilst retaining the interconnected signal within the data (Egozcue, 2005). There are also multiple ways of elucidating these compositional fingerprints, offering a range of tools to the potential analyst (Aitchison, 2005).

Compositional data analysis (CoDA) approaches have developed a range log ratio transformation which take account of the compositional nature of data, though the total sum may not always be known but this varies between transformations (Pawlowsky-Glahn and Egozcue, 2001; Egozcue et al. 2003; Tolosana-Delgado 2012; McKinley et al. 2013). Log ratio transformations reduce the dimensions of a dataset and the selection of the pwlr (pairwise log ratio), alr (additive log ratio), clr (centred log ratio) or ilr (isometric log ratio) transformations, is dependent on the task at hand (Filzmoser and Hron, 2009). Once data are transformed, common forms of analysis are correlation coefficients and principal component analysis (PCA) to assess the underlying relations between the constituent parts (Kynčlová et al., 2017). This is now commonly done in bioinformatics, where genetic sequence data are constrained by the assay technologies ability to record counts of genetic data (Quinn et al., 2018). Consequently, it is these patterns of correlations that form the unique fingerprint that can be used to interrogate complex environmental trends. This approach has had 
success in geochemistry where log ratio transformations on trace elements can reveal more information about a soil horizon than the "traditional" log transformation but can also produce reliable comparisons between soil horizons (Reimann et al., 2017).

\subsection{Assessing Causal Trends from Compositional Signals}

Assessing trends between sub-compositions remains challenging, the family of ilr transformations have been argued to be the best option when analysing compositional data as the isometric transformation removes collinearity from data which the clr transformation can produce as values scaled to sum to zero. In turn, use of an ilr transform may be particularly useful when compositions contain meaningful sub-compositions as this log-ratio can accommodate this level of complexity (Filzmoser et al., 2009). This is most true of geochemical datasets comprising a high number of elements where there are multiple sub-compositions representing signals from multiple soil types and parent rocks. In ecotoxicology it is the transference of the compositional signal at source to sink which is of concern. In this case the clr transformation is helpful as this log-ratio both preserves the original variable names and reduces complexity allowing for clearer comparisons, particularly when few elements (10 or fewer) are the subject of study (Egozcue et al., 2003). This is often true in the toxicological context when it is potentially toxic elements (PTEs) and not toxicologically inert elements which are the subject of study (McKinley et al., 2013; Barsby et al., 2012). Previously, the focus has been estimating bioavailability and bioaccessibility fractions from soil directly as well as identifying PTE sources and domains (Palmer et al., 2013; Mcllwaine et al., 2015; Palmer et al., 2015; Plouffe et al., 2015). More recently assessing the causal trends between PTEs and public health data has become a high priority as CoDA can provide a degree of insight so long as the mechanisms are well understood and it is these mechanisms which impart the most knowledge in ecotoxicology (McKinley et al., 2013; Jackson et al., 2016; McKinley et al. 2020a,b). 
Within the life sciences, compositional methods have been adopted in microbiology as studies produce datasets that culminate to an arbitrary total that is compositional in nature (Gloor et al., 2017). For example, in shotgun metagenomics of environmental samples, the media are compositional from the point of sample collection as all members of the microbiome represent distinct parts of a whole and when DNA is dissociated from cells a reference library can be used to approximate the proportional occurrences of taxa relative to the whole solution (Calle, 2019). In ecotoxicology, there is space for compositional methods to greatly inform our knowledge of PTE accumulation but most importantly identifying associations between individual animals and PTEs is essential to identify potential mechanisms by which PTEs move through the environment. Currently, the bioaccumulation pathway (accumulation through diet) is well understood (Zietara et al., 2019) and there has been research that has informed our understanding of the bioaccessibility pathway (accumulation through environmental exposure) (Miranda et al., 2009). However, the standard approach in PTE ecotoxicology remains either to report totals or averages of accumulation, or the log10 transformation is used to address the skew to the right, which is common in PTE data, followed by a statistical analysis. The issue is that PTEs in soil are compositional in nature and that ratio orientated signal remains after accumulation, which the log10 transformation is not easily able to accommodate, as data are transformed without preserving the relative compositional signal. Hence the question remains, what are the differences between these options and what are the strengths of the compositional approach when compared to the more conventional use of the log 10 transformation or untransformed data? 
Badger liver, kidney and muscle (right forelimb) were dissected from road traffic accident (RTA) specimens between November 2017 and October 2018, from across Northern Ireland. Samples were stored at $-20^{\circ} \mathrm{C}$ and then freeze dried for a period of 72 hours, homogenised with an agate pestle and mortar, $0.5 \mathrm{~g}$ of homogenised sample was then acid digested in a digestion microwave (specification: CEM Corporation, MARS 240/50) in a solution of $10 \mathrm{~mL}$ of $\mathrm{HNO}_{3}(65 \% \mathrm{v} / \mathrm{v}), 2 \mathrm{~mL}$ of $\mathrm{H}_{2} \mathrm{O}_{2}(30 \% \mathrm{v} / \mathrm{v})$ digested for: $0-1600 \mathrm{~W}, 20-220^{\circ} \mathrm{C}$ for 30 minutes, $0 \mathrm{~W}, 20^{\circ} \mathrm{C}$ for 30 minutes and each digestion was run alongside a blank control and the beef reference material RM 8414 was used to validate results (Ihnat, 1994). contamination and a dilution factor was used to take account of sample dilution; half of the detection limit was used in the case of no detectable sample. next closest point) that killed each individual badger was taken. The soil data was collected from the Tellus Survey, a publicly available geochemical dataset produced by the Geological Survey of Northern Ireland (Smyth, 2007; Young and Donald, 2013). All the soil samples are presumed to represent signals from the area in the badger occupied before its death.

\subsection{Statistics}

172 Cluster plots were made for each dataset, using the CoDA clr transformation, the log10 transformation and the untransformed data (unt), using the ward.D method with Euclidean distance and Tanglegrams were produced using the package dendextend in R (Galili, 2015). Tanglegrams, 
comparative plots between two dendrograms with the same end points, were produced from these cluster plots to demonstrate the differing degrees of congruence between the different data types within each of the four datasets (Liver, Muscle, Kidney and Soil) (Figure 1 - 4). Only the clr and log10 data were suitable for the next phase of analysis due to homogeneity in the unt dataset. Bootstrapping (random sampling with replacement) set to 1000 repetitions was used on the data (Suzuki and Shimodaira, 2006) and complex heatmaps were produced using spearman's correlation, to assess the underlying signal in the data (Reimann et al., 2017). Lastly, principal component analysis was conducted, using the princomp function in R, to assess the differences between the clr and $\log 10$ transformations ability to separate trends of individual PTEs within the datasets (Team, 2013). These data have been published previously and for information on PTE accumulation refer to Mullineaux et al., (2020).

\section{Results}

The Tanglegrams for the Liver (Figure 1 A), Muscle (Figure 1 B), Kidney (Figure $1 \mathrm{C}$ ) and Soil (Figure 1

D) datasets show high levels of congruence between the clr and log10 transformations and low levels of congruence between $\mathrm{clr} / \log 10$ and unt. The distance metrics between clr and log10 differ by a factor of 2-3, while the unt distance metrics are much greater showing that the unt dendrograms are more poorly resolved than both the clr and log10 dendrograms. Though the clr and log10 Liver, Muscle and Kidney (Figure 1 A I, Figure 1 B I, Figure 1 C I) dendrograms show a higher degree of congruence than the equivalent soil dendrograms (Figure $1 \mathrm{D} \mathrm{I}$ ). The unt dendrograms also show a "pull to the right" indicative of a poorly resolved dendrogram with a group of clades containing few leaves and a long branches indicative of outliers within that clade (Figure $1 \mathrm{~A} \mathrm{II/III,}$ Figure $1 \mathrm{~B} \mathrm{II} / \mathrm{III}$, Figure $1 \mathrm{C} \mathrm{II/III,} \mathrm{Figure} 1 \mathrm{D} \mathrm{II} / \mathrm{III})$. Overall, unt shows signs of producing mixed signals within the data making it inappropriate for the analysis of PTEs in both organic tissue and soil. 

accumulation between groups of individual badgers, but these diagrams do not show which combinations of PTEs are contributing to these patterns. 

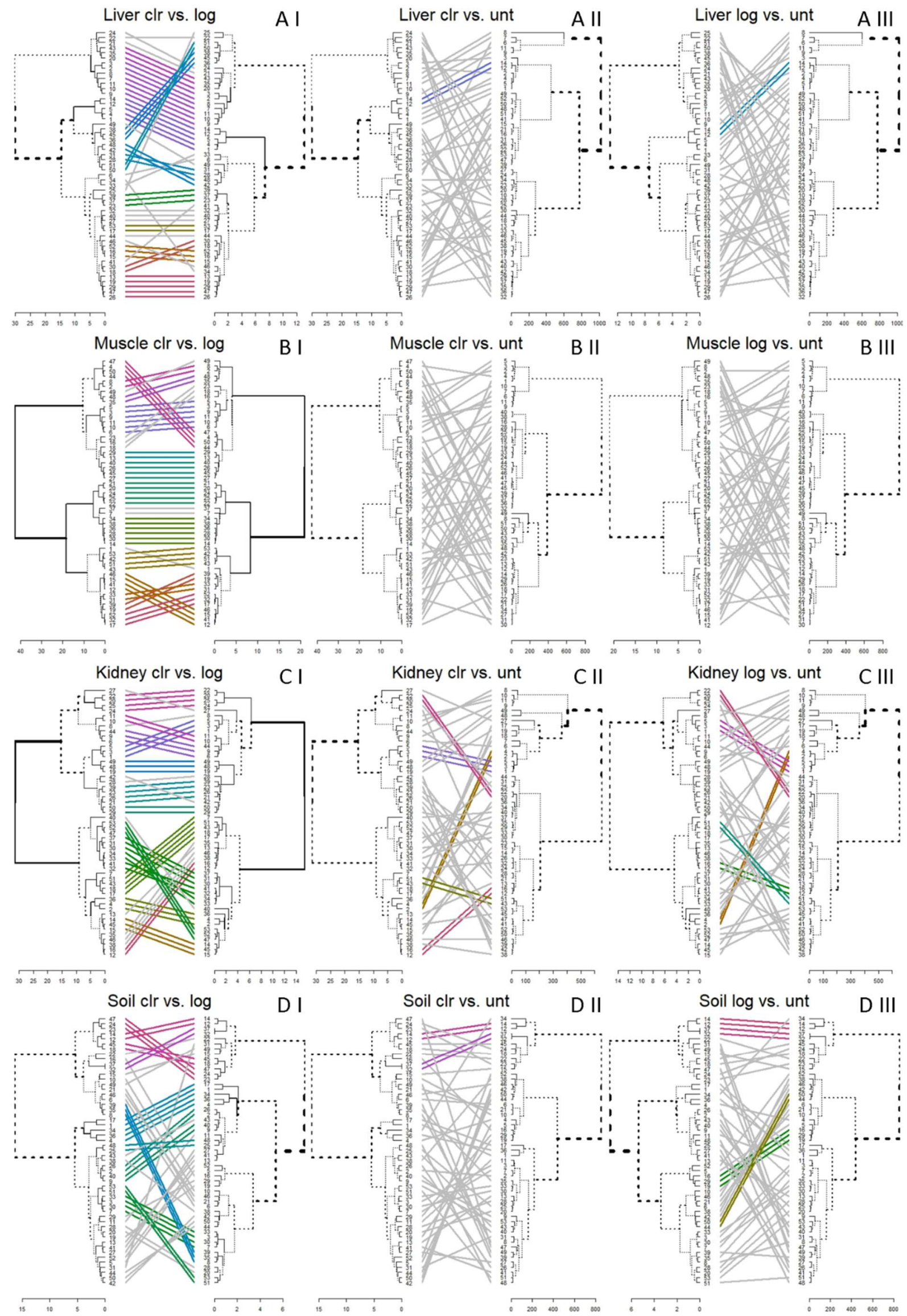
Figure 1: Liver (A I) clr vs. $\log 10$ (A II) clr vs. unt (A III) log vs. unt. A I is most congruent, A II and A III equally so; Muscle (B I) clr vs. $\log 10$ (B II) clr vs. unt (B III) log vs. unt. B I is most congruent, $\mathrm{B}$ II and B III equally so; Kidney (C I) clr vs. log10 (C II) clr vs. unt (C III) log vs. unt. CI is most congruent, C II and C III equally so; Soil (D I) clr vs. $\log 10$ (D II) clr vs. unt (D III) log vs. unt. D I is most congruent, D III and then D II. Branches with solid lines represent clades which were resolved identically in both trees, whilst perforated lines represent clades resolved non-identically, thus containing individuals which did not cluster together in the corresponding dendrogram.

The homogeneity of the unt datasets prevented them from being included in the next phase of analysis and correlation heatmaps were created for both clr and log10 following the method described by Reimann (2017). All elements are included in the clr heatmaps due to the compositional approach being able to estimate values for missing data given that all values are treated as inter-related ratios. Whilst $\mathrm{As}$ is excluded from Figure $2 \mathrm{~B}, \mathrm{D}$ and $\mathrm{F}, \mathrm{Pb}$ is also excluded from Figure $2 \mathrm{D}$ as log 10 cannot account for missing data, whilst all elements remain in Figure $2 \mathrm{~A}, \mathrm{C}$, $\mathrm{E}, \mathrm{G}$ and $\mathrm{H}$. However, though clr can account for missing data, that alone is not cause for its inclusion, the adjoining trees in Figure $2 \mathrm{C}$ and $\mathrm{D}$ as well as $\mathrm{E}$ and $\mathrm{F}$ show that for Muscle and Kidney both clr dendrograms have shown a pull to the right and that is not seen in the equivalent log10 trees showing the signal remains stronger due to the exclusion of missing data.

Throughout all PTE clr dendrograms and heatmaps distinct patterns can be seen (Figure 2 A, $\mathrm{C}, \mathrm{E}, \mathrm{G})$. In the three tissue plots $\mathrm{Al}, \mathrm{Cu}, \mathrm{Cr}$ and $\mathrm{Sr}$ can be seen to cluster together consistently and the same cluster is seen in the clr soil tree with the inclusion of NI Se and Zn cluster consistently in all clr dendrograms with the inclusion of Mo in the clr Liver plot and the inclusion of $\mathrm{As}$ and $\mathrm{Pb}$ in $\mathrm{clr}$ Muscle plot. As and $\mathrm{Pb}$ also cluster together consistently in all three tissue dendrograms with the inclusion of Mo in the clr Soil plot. Mo and Ni are also closely associated and cluster together in both the clr Muscle, and Kidney dendrograms and are closely associated in paired groups in the clr Liver dendrogram. However, both Mo and Ni are at opposite ends of the clr Soil dendrogram and this is 

the only observable deviation between the clr tissue dendrograms and the clr Soil dendrogram (Figure $2 \mathrm{~A}, \mathrm{C}, \mathrm{E}$ and $\mathrm{G}$ ). These shared patterns between the clr plots are not seen in the log10 plots (Figure $2 \mathrm{~B}, \mathrm{D}, \mathrm{F}$ and $\mathrm{H}$ ), $\mathrm{Al}, \mathrm{Cu}, \mathrm{Cr}$ and $\mathrm{Sr}$ cluster closely in these dendrograms, but it is not as clear with the inclusion of $\mathrm{Ni}$ in the $\log 10$ Liver plot, $\mathrm{Zn}$ in the clr Muscle plot and dissociation in the $\log 10$ Kidney and Soil plots. Se and Zn only cluster in the log10 Liver and Kidney plots and are dissociated in the $\log 10$ Muscle and Soil plots, both also cluster in the soil plots. As is excluded from all log10 tissue dendrograms and $\mathrm{Pb}$ from the log10 Muscle dendrogram, so the $\mathrm{As}$ and $\mathrm{Pb}$ cluster did not have the opportunity to arise under the log10 approach. However, As and $\mathrm{Pb}$ have clustered with $\mathrm{Mo}$ and $\mathrm{Se}$ in the $\log 10$ soil plot, and $\mathrm{Mo}$ is associated with $\mathrm{As}$ and $\mathrm{Pb}$ in the clr Soil dendrogram. Mo and $\mathrm{Ni}$ only cluster together in the $\log 10$ Muscle dendrogram and are disassociated in all other log10 dendrograms (Figure $2 \mathrm{~B}, \mathrm{D}, \mathrm{F}$ and $\mathrm{H}$ ).

239

240 

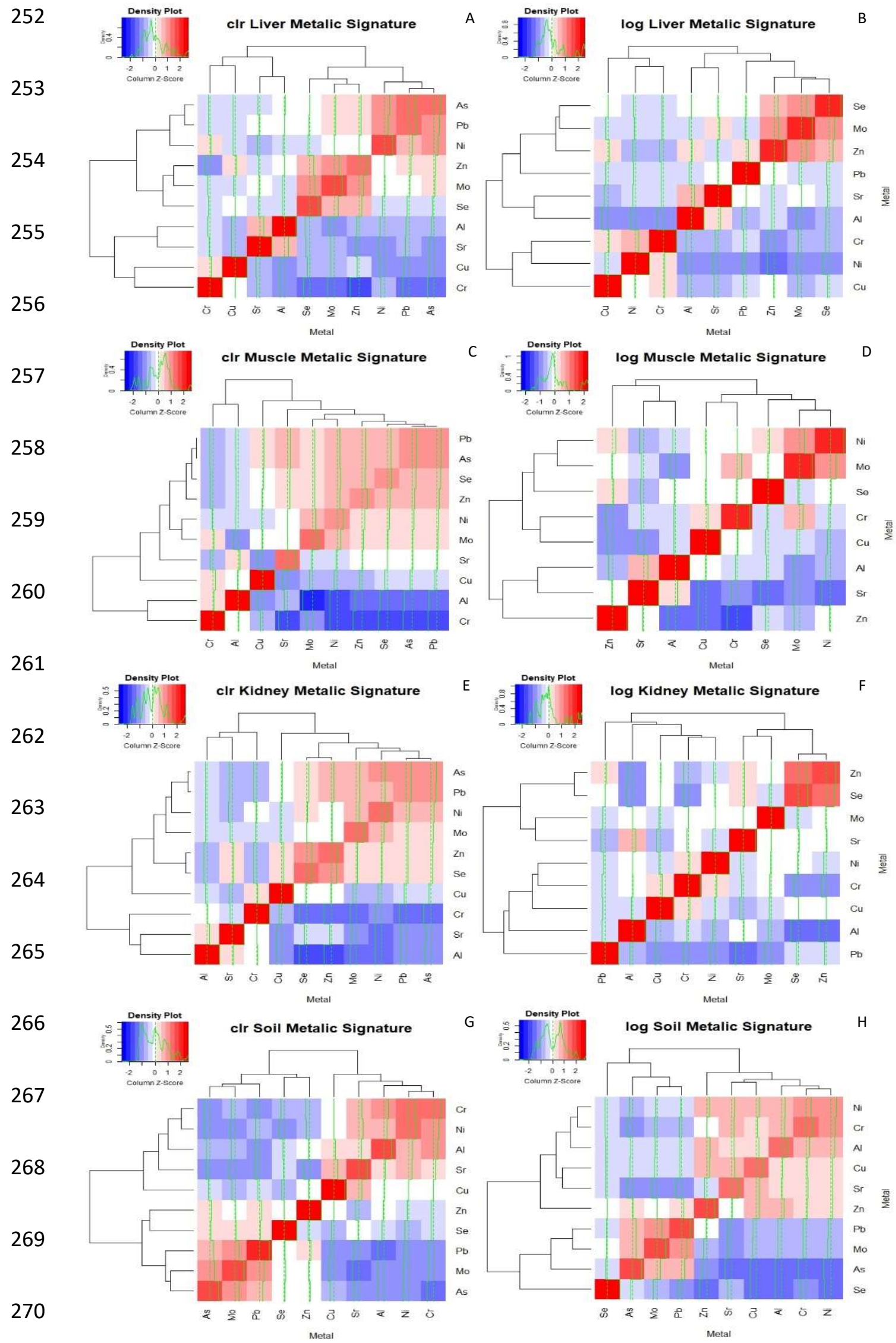
Kidney, (G) clr Soil, (H) log10 Soil. The green dotted lines in each branch correspond to 0 and the solid green line shows the degree of shift from the 0 value, as shown in the density plot. captured more variance than the log10 PCAs, as higher degrees of variance are seen under clr in PC1 and PC2 than log10 (Figure 3 A, C, E and G; Figure 4 A, C, E and G). The clr Liver, Muscle and Kidney biplots are highly similar in the directionality of the elements, though this relationship is not shared with soil (Figure 3 B, D, F and H). However, for log10, Muscle and Kidney show a similar pattern of directionality, but $\mathrm{Cu}$ is more prominent in the Liver under log10, like clr, no clear relationship can be observed with Soil (Figure 4 B, D, F and H). Soil under clr, shows multi-directionality in the eigenvectors, whilst under log10, the eigenvectors are more correlated (Figure 3 H; Figure 4 H). More variance is accounted for by the clr transformation in all scenarios, but no clear similarities can be seen with soil under both transformations. Overall, the angles between the eigenvectors are more obtuse under clr and more acute under log10. Thus, demonstrating that the compositional relationships between elements have been more clearly resolved using clr rather than log10. biplots the eigenvectors for $\mathrm{Al}, \mathrm{Cr}, \mathrm{Cu}$ and $\mathrm{Sr}$ have the longest eigenvectors, indicating they are consistently contributing the highest degrees of variance to PCs 1 and 2 in these analyses with the addition of $\mathrm{Ni}$ in the clr Kidney and Soil plots. Se and Zn remain closely affiliated across all clr biplots indicating a strong correlation but are associated with Mo in the clr Liver plot, associated with As, Ni and $\mathrm{Pb}$ in Muscle plot (likely due to reduced signal in this tissue type) and remain distinct in the clr Soil biplot. As and $\mathrm{Pb}$ are also closely associated across all clr biplots, showing a correlation and have short eigenvectors indicating they contribute a low degree of variance to PCs 1 and 2, though they are associated with $\mathrm{Ni}$ in the clr Liver biplot, Ni, Se and $\mathrm{Zn}$ in the clr Muscle biplot and Mo in the clr 

between eigenvectors is made possible by these clr biplots, demonstrating the compositional relationships between the eigenvectors (Tolosana-Delgado, and McKinley, 2016). In the log10 biplots show mono directionality indicating that for these datasets log10 was not able to separate the compositional signals of these elements. In the log10 Liver plot the eigenvectors for Mo, Se and $\mathrm{Zn}$ are closely affiliated and $\mathrm{Ni}$ and $\mathrm{Pb}$ are also closely affiliated. In the log10 soil biplot, the eigenvectors these two groupings (Figure 4 B, D, F and H) (Supplementary Material, Table S1-S8). 
A

320

321

322

323

324

325

326

327

328

329

330

331

332

333

334

335

336

337

338

C

E

35
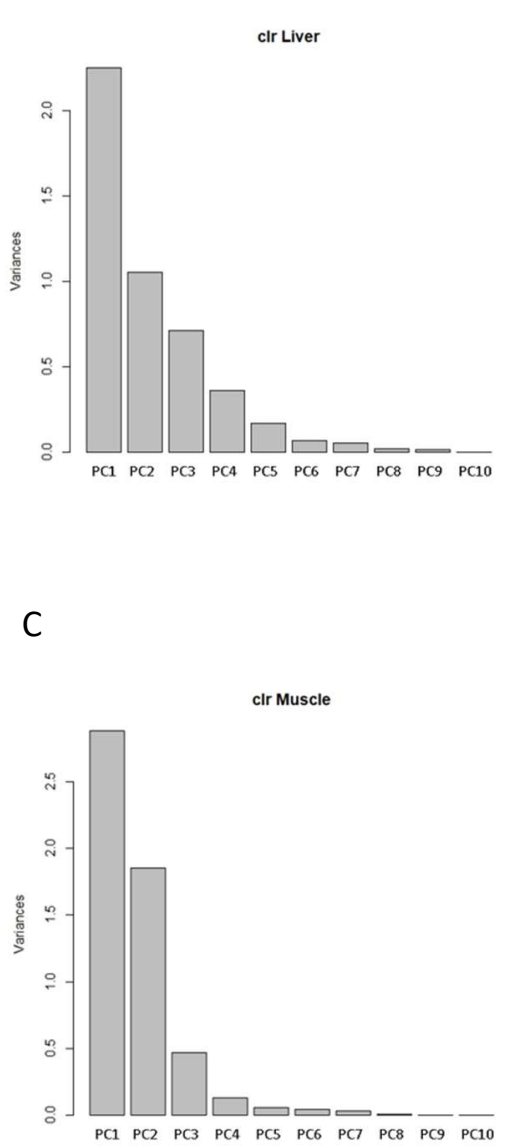

clr Kidney

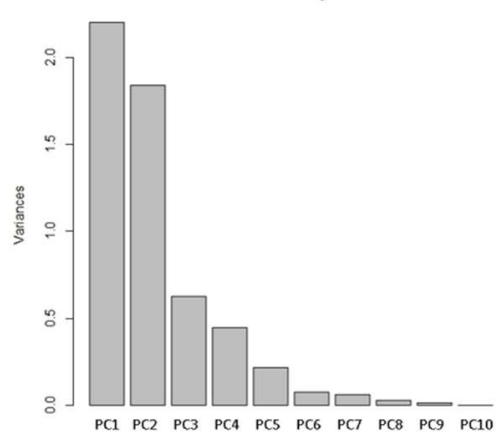

G

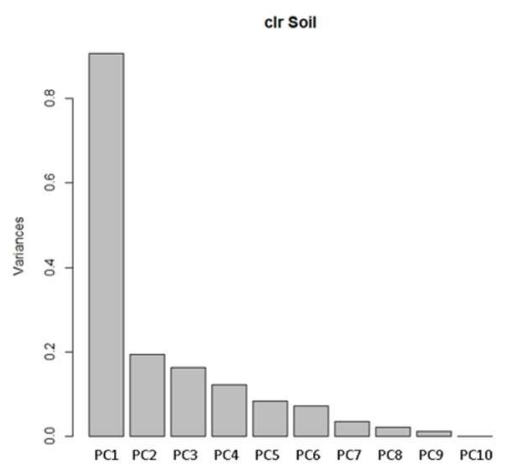

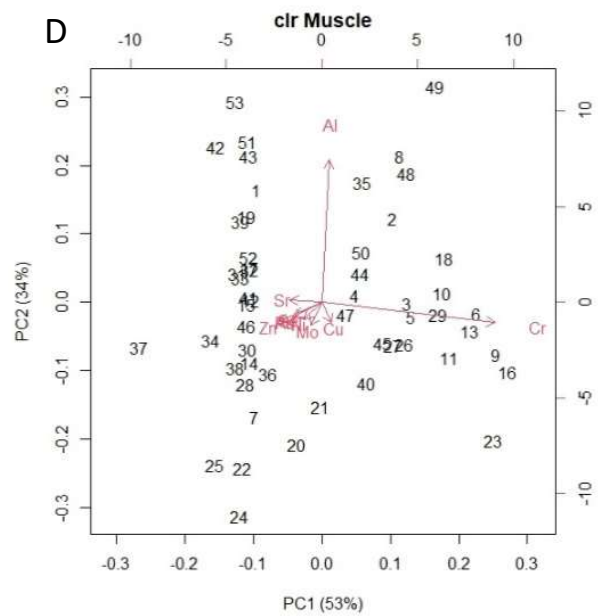
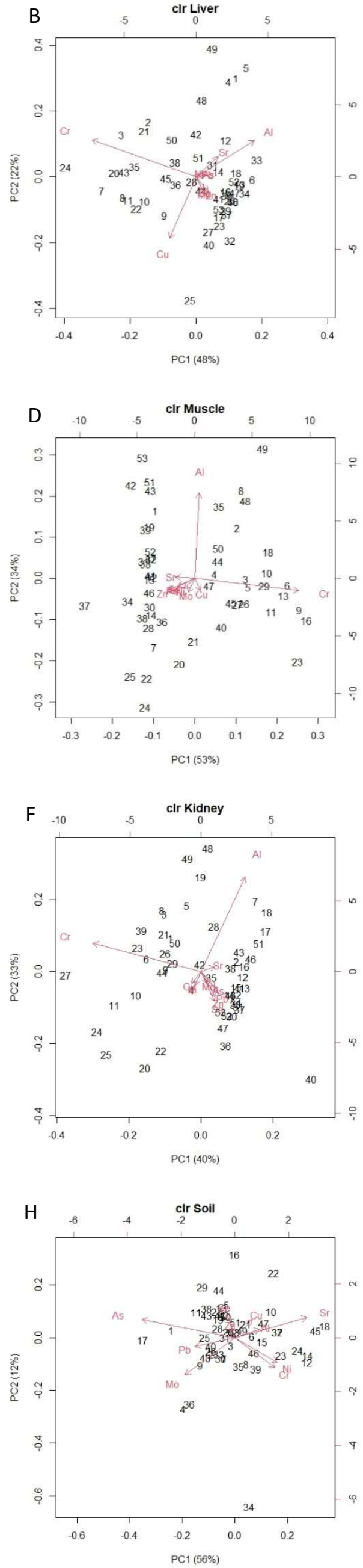

clr Kidney scree plot, (F) clr Kidney biplot, (G) clr Soil scree plot, (H) clr Soil biplot.

341

342

343

344

345

346

347

348

349

350

351

352

353

354

355

356

357

358 
A

360

361

362

363

364

365

366

367

368

369

370

371

372

373

374

375

376

377

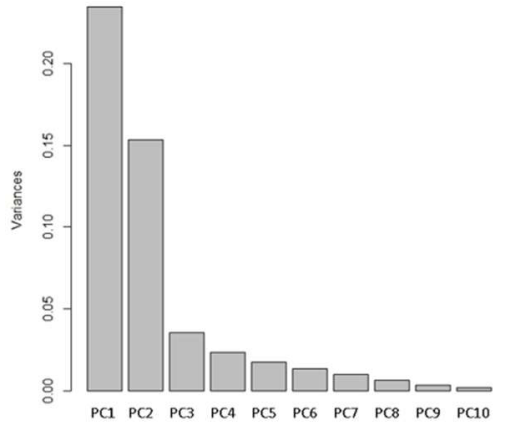

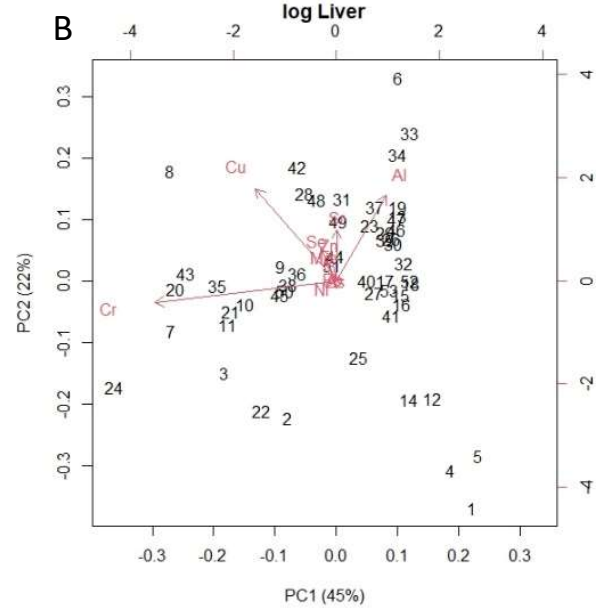
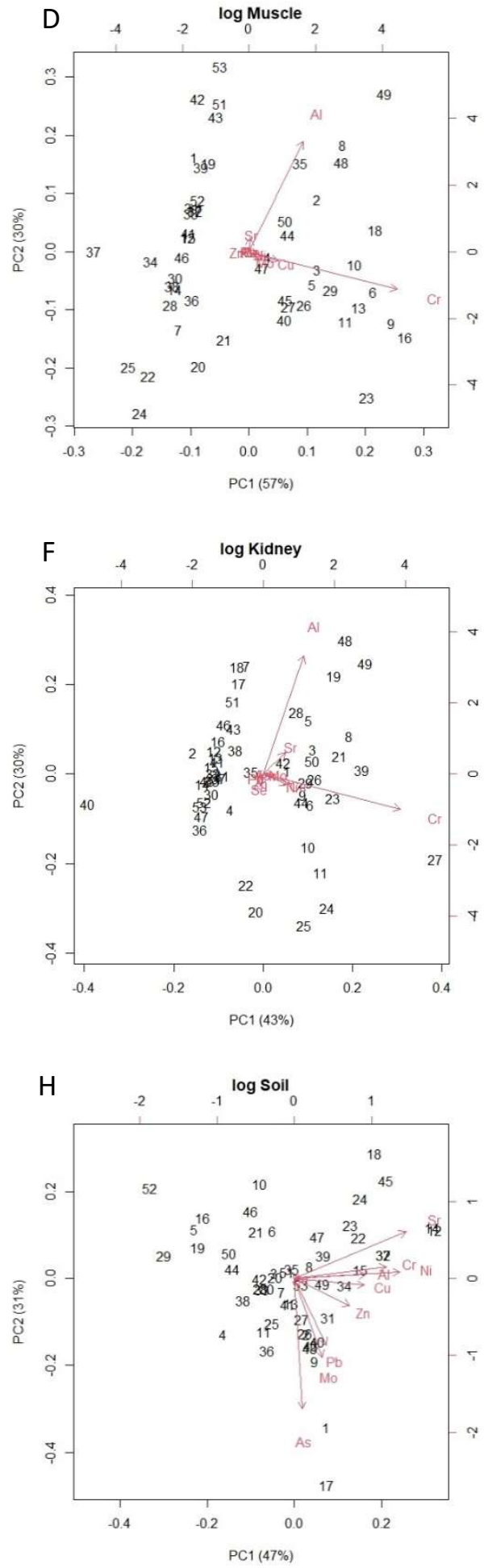
Figure 4: (A) $\log 10$ Liver scree plot, (B) log10 Liver biplot, (C) log10 Muscle scree plot, (D) log10 Muscle biplot, (E) log10 Kidney scree plot, (F) log10 Kidney biplot, (G) log10 Soil scree plot, (H) log10 Soil biplot.

4. Discussion

In this comparison, it can be qualitatively noted that the clr transformation has "opened up" the data more effectively than $\log 10$, even though both transformations produce highly congruent dendrograms (Figure $1 \mathrm{~A}, 2 \mathrm{~A}, 3 \mathrm{~A}$ ) clr retains a higher distance metric showing that more variance has been preserved in the data and the data are not "over-corrected "as the compositional balances in the data have been considered (Aitchison, 1982). Another advantage remains that clr data can account for a variable with many values represented by half the detection limit. However, the norm in the geosciences is that variables with far too few observations should be removed from the analysis but in the context of ecotoxicology where a source (soil) and sink (badger) need to be considered in parallel, patterns cannot be assessed comparatively if elements are removed from tissue data, for it is similarities and deficiencies in the compositions that need to be considered when assessing trends of accumulation. These trends can be compared in the biplots of the PCA analysis which is a standard approach in compositional analysis (Figure 3) (Aitchison and Greenacre, 2002; Aitchison, 1983). Though, it should be noted that the algebraic descriptions and resulting geometries of each data type are not directly comparable and that the results are a demonstration of the differences between these approaches,

When compared, the clr complex heatmap plots show a more consistent pattern than their $\log 10$ equivalents (Figure 2). The clr transformation allows for the compositional patterns to be identified, as shown by the angles in the eigenvectors (Figure $3 \mathrm{~B}, \mathrm{D}, \mathrm{F}$ and $\mathrm{H}$; Figure $4 \mathrm{~B}, \mathrm{D}, \mathrm{F}$ and $\mathrm{H}$ ), and these distinct clusters can identify source too sink trends (Egozcue and Pawlowsky-Glahn, 
signal can be attributed to the mafic zone in the North East of Northern Ireland with potentially some influence from the granitic Mourne Mountains in the South. The Mo, Se and Zn signal can be attributed to the Silurian greywacke and Shale of the South East and Ards Peninsula which is known to be a mineralising zone. The $\mathrm{As}, \mathrm{Ni}$ and $\mathrm{Pb}$ signal could be attributed to the under sampling seen in the tissue data creating homogeneity between these variables, though there is likely an anthropogenic signal in this grouping associated with urbanisation and industrialisation in the East and South East of Northern Ireland (Smyth, 2007). These clusters are identifiable in both the badger tissue and soil data and demonstrate how the compositional approach can show this source too sink relationship.

\subsection{Compositional Analysis in the Life Sciences}

Compositional analysis is not new to the life sciences, recently the compositional approach has been adopted in microbiology as species present in a microbiome collate to a total imposed on the data by the instrument used (Gloor et al., 2017; Rivera-Pinto et al., 2018) and alternative compositional frameworks have been designed (Brill et al., 2019). In the experimental context of microbiology, the compositional approach has been applied to understanding cellular activity, given a proportionate baseline one can measure what is changing in relation to a cause of change (Quinn et al., 2019). This philosophy has been applied successfully to understand changes in microbial communities in relation to factors like temperature in alpine habitats, seasonality in marine systems and the evolution of dental calculus microbiomes and how they vary temporally (Frindte et al., 2019; Aluladell et al., 2018; Brealey et al., 2019). In turn, there is a basis for the compositional approach in the life sciences and as demonstrated here it offers important insights in an ecotoxicological context (Mullineaux et al., 2020).

\subsection{Compositional Analysis in the Geosciences and Medical Geology}

In the geosciences, compositional methods are well established and have opened the possibility for clearer assertions to be made about soils and environmental pollution, allowing for causative trends 
to be identified (Aitchison, 1994; Buccianti et al., 2006). Such causative trends are identified in the field of medical geology, where large amounts of public health data, when made accessible, can be used to evaluate the risks of pollutants and contaminants (McKinley et al., 2013; McKinley et al. $2020 a, b)$. However, in ecotoxicology, it can be difficult to identify the mechanisms through which pollutants and contaminants move through the environment, and it is here where the compositional approach offers more power. Especially, as demonstrated above, where ratios at source can be matched with those at sink placed in a wider geospatial context. In medical geology, by measuring concentrations of individual PTEs and how they co-vary (Mcllwaine et al., 2015), combining this information with bioaccessibility quotients (Barsby et al., 2012; Palmer et al., 2013; Palmer et al., 2015) and utilising public health data or another metric, compositional methods can identify specific pollutants and contaminants which are potentially causal for various health conditions (Jackson et al., 2016). Therefore, in PTE ecotoxicology, if sources and sinks are to be identified effectively, patterns of accumulation, trends and mechanisms identified, then compositional methods should be considered an effective tool in an analyst's arsenal. Consequently, as demonstrated here understanding processes of PTE accumulation requires accounting for the compositional signals within PTE data.

\section{Conclusion}

The $\log 10$ transformation may be acceptable for understanding PTE accumulation patterns at the point of the individual as demonstrated by the high degrees of congruence between log10 and clr for individual badgers (Figures $1 \mathrm{~A}-\mathrm{D}$ ). However, it is not acceptable when looking at patterns at the population level when looking to elucidate trends between PTEs (Figure 2). This is further seen when looking at the compositional patterns of PTEs between individual tissues and soils (Figure 3 and 4) because the clr transformation highlights the similarities between the tissue types and the disparity 

mechanisms of PTEs from soils to the biosphere.

We would like to thank Sophie Redpath, John Meneely, Julia Simpson, Manus Carey, Julie-Anne Hanna and David Parker of Queens University Belfast for their support in the lab work phase of this project. We would also like to thank Bob Hanna and AFBI Stormont for their support throughout this research. We are also thankful to the Department for the Economy of Northern Ireland for providing funding for this research. The Author is also thankful to the anonymous reviewers for their feedback and valuable insights.

462

References

Aitchison, J., 1982. The statistical analysis of compositional data. Journal of the Royal Statistical

Aitchison, J., 1983. Principal component analysis of compositional data. Biometrika, 70(1), pp.57-65,

Aitchison, J. (1994). Principles of compositional data analysis. Lecture Notes-Monograph Series, 73-

Aitchison, J. and Egozcue, J.J., 2005. Compositional data analysis: where are we and where should we be heading?. Mathematical Geology, 37(7), pp.829-850, 10.1007/s11004-005-7383-7 
475 Auladell, A., Sánchez, P., Sánchez, O., Gasol, J.M. and Ferrera, I., 2018. Long-term seasonality of

476 marine photoheterotrophic bacteria reveals low cohesiveness within the different

477 phylogroups. bioRxiv, p.316059, 10.1101/316059

Barsby, A., McKinley, J.M., Ofterdinger, U., Young, M., Cave, M.R. and Wragg, J., 2012.

Bioaccessibility of trace elements in soils in Northern Ireland. Science of the Total Environment, 433, pp.398-417, 10.1016/j.scitotenv.2012.05.099

Brealey, J.C., Leitão, H.G., Xu, W., Dalén, L. and Guschanski, K., 2019. Dental calculus as a tool to study the evolution of the oral microbiome in mammals. bioRxiv, p.596791, 10.1101/596791

Brill, B., Amir, A. and Heller, R., 2019. Testing for differential abundance in compositional counts the geosciences: From theory to practice. Geological Society of London.

Chapman, P.M., 2007. Determining when contamination is pollution-weight of evidence determinations for sediments and effluents. Environment International, 33(4), pp.492-501, $\underline{10.1016 / i . e n v i n t .2006 .09 .001}$

Egozcue, J.J. and Pawlowsky-Glahn, V., 2019. Compositional data: the sample space and its structure. TEST, 28(3), pp.599-638, 10.1007/s11749-019-00670-6

Egozcue, J.J. and Pawlowsky-Glahn, V., 2005. Groups of parts and their balances in compositional data analysis. Mathematical Geology, 37(7), pp.795-828, 10.1007/s11004-005-7381-9 

pp.621-632, 10.1002/env.966

Frindte, K., Pape, R., Werner, K., Löffler, J. and Knief, C., 2019. Temperature and soil moisture control microbial community composition in an arctic-alpine ecosystem along elevational and microtopographic gradients. The ISME Journal, p.1, 10.1038/s41396-019-0409-9 hierarchical clustering. Bioinformatics, 31(22), pp.3718-3720, 10.1093/bioinformatics/btv428 compositional: and this is not optional. Frontiers in microbiology, 8, p.2224, Powder (NIST RM 8415) and Whole Milk Powder (NIST RM 8435) Reference Materials for essential and toxic major, minor and trace element constituents. Fresenius' journal of analytical chemistry, 348(7), pp.459-467, 10.1007/BF00325312

514 Jackson, C.E., McKinley, J.M., Ofterdinger, U., Fogarty, D., Atkinson, P.M. and Palmer, S., 2016.

515 Investigating relations between environmental toxins in Northern Irish soils and streams and Chronic

516 Kidney Disease prevalence. Applied Geochemistry, 75, pp.236-246,

\section{$517 \quad$ 10.1016/j.apgeochem.2016.10.016}

518 Kynčlová, P., Hron, K. and Filzmoser, P., 2017. Correlation between compositional parts based on symmetric balances. Mathematical Geosciences, 49(6), pp.777-796, 10.1007/s11004-016-9669-3 

affecting geochemical analytical techniques for measuring element concentrations in soil. Environmental Science and Pollution Research, 22(8), pp.6364-6371, 10.1007/s11356-015-4204-

McKinley, J.M., Hron, K., Grunsky, E.C., Reimann, C., de Caritat, P., Filzmoser, P., van den Boogaart, K.G. and Tolosana-Delgado, R., 2016. The single component geochemical map: Fact or fiction?. Journal of Geochemical Exploration, 162, pp.16-28, 10.1016/j.gexplo.2015.12.005

McKinley, J.M., Mueller, U., Atkinson, P.M., Ofterdinger, U., Cox, S.F., Doherty, R., Fogarty, D., Egozcue, J.J. and Pawlowsky-Glahn, V., 2020a. Chronic kidney disease of unknown origin is associated with environmental urbanisation in Belfast, UK. Environmental Geochemistry and Health, pp.1-18, 10.1007/s10653-020-00618-y McKinley, J.M., Mueller, U., Atkinson, P.M., Ofterdinger, U., Jackson, C., Cox, S.F., Doherty, R., Fogarty, D., Egozcue, J.J. and Pawlowsky-Glahn, V., 2020b. Investigating the influence of environmental factors on the incidence of renal disease with compositional data analysis using balances. Applied Computing and Geosciences, p.100024, 10.1016/j.acags.2020.100024

McKinley, J.M., Ofterdinger, U., Young, M., Barsby, A. and Gavin, A., 2013. Investigating local relationships between trace elements in soils and cancer data. Spatial statistics, 5, pp.25-41, 10.1016/i.spasta.2013.05.001 2009. Metal accumulation in cattle raised in a serpentine-soil area: relationship between metal concentrations in soil, forage and animal tissues. Journal of Trace Elements in Medicine and Biology, 23(3), pp.231-238, 10.1016/j.jtemb.2009.03.004 

approach. Science of The Total Environment, p.143087.

Palmer, S., Mcllwaine, R., Ofterdinger, U., Cox, S.F., McKinley, J.M., Doherty, R., Wragg, J. and Cave,

Palmer, S., Ofterdinger, U., McKinley, J.M., Cox, S. and Barsby, A., 2013. Correlation analysis as a tool to investigate the bioaccessibility of nickel, vanadium and zinc in Northern Ireland soils. Environmental geochemistry and health, 35(5), pp.569-584, 10.1007/s10653-013-9540-0 zinc at the global scale using geochemical modelling and soil archetypes. The international journal of life cycle assessment, 20(4), pp.527-540, 10.1007/s11367-014-0841-z for the compositional analysis of any-omics data. GigaScience, 8(9), p.giz107, $\underline{10.1093 / g i g a s c i e n c e / g i z 107 ~}$ compositions: an outlook and review. Bioinformatics, 34(16), pp.2870-2878,

561 Reimann, C., Filzmoser, P., Hron, K., Kynčlová, P. and Garrett, R.G., 2017. A new method for 562 correlation analysis of compositional (environmental) data-a worked example. Science of the Total 
567 Smyth, D., 2007. Methods used in the Tellus geochemical mapping of Northern Ireland.

Retrieved from: http://nora.nerc.ac.uk/id/eprint/14008

Suzuki, R. and Shimodaira, H., 2006. Pvclust: an R package for assessing the uncertainty in

570 hierarchical clustering. Bioinformatics, 22(12), pp.1540-1542, 10.1093/bioinformatics/btl117 geology, 280, pp.60-79, 10.1016/i.sedgeo.2012.05.005 components and trace elements in the Tellus soil geochemistry survey (Northern Ireland). Applied Geochemistry, 75, pp.263-276, 10.1016/j.apgeochem.2016.05.004 of cadmium and lead, but not zinc, are higher in red fox tissues than in rodents-pollution gradient study in the Małopolska province (Poland). Environmental Science and Pollution Research, 26(5), 
587

588

590

591

\begin{tabular}{|l|l|l|l|l|l|l|l|l|l|l|}
\cline { 2 - 9 } \multicolumn{1}{c|}{} & PC1 & PC2 & PC3 & PC4 & PC5 & PC6 & PC7 & PC8 & PC9 & PC10 \\
\hline $\begin{array}{l}\text { Standard } \\
\text { Deviation }\end{array}$ & 1.5004639 & 1.0261168 & 0.8444990 & 0.60227493 & 0.41041880 & 0.25735762 & 0.22910929 & 0.131621914 & 0.114673283 & $5.875111 \mathrm{e}-09$ \\
\hline $\begin{array}{l}\text { Proportion } \\
\text { of Variance }\end{array}$ & 0.4792374 & 0.2241265 & 0.1518091 & 0.07721278 & 0.03585536 & 0.01409853 & 0.01117339 & 0.003687704 & 0.002799137 & $7.347369 \mathrm{e}-18$ \\
\hline $\begin{array}{l}\text { Cumulative } \\
\text { Proportion }\end{array}$ & 0.4792374 & 0.7033640 & 0.8551731 & 0.93238588 & 0.96824124 & 0.98233977 & 0.99351316 & 0.997200863 & 1.000000000 & $1.000000 \mathrm{e}+00$ \\
\hline
\end{tabular}

Table S2: Muscle clr PCA output.

\begin{tabular}{|c|c|c|c|c|c|c|c|c|c|c|}
\hline & PC1 & PC2 & PC3 & PC4 & PC5 & PC6 & PC7 & PC8 & PC9 & PC10 \\
\hline $\begin{array}{l}\text { Standard } \\
\text { Deviation }\end{array}$ & 1.697437 & 1.3614065 & 0.68496000 & 0.3587262 & 0.23659803 & 0.210074483 & 0.16760999 & 0.08793572 & 1.199301e-08 & 5.126317e-09 \\
\hline $\begin{array}{l}\text { Proportion } \\
\text { of Variance }\end{array}$ & 0.526888 & 0.3389273 & 0.08579488 & 0.0235319 & 0.01023654 & 0.008070075 & 0.00513725 & 0.00141404 & $2.630193 e-17$ & $4.805535 \mathrm{e}-18$ \\
\hline $\begin{array}{l}\text { Cumulative } \\
\text { Proportion }\end{array}$ & 0.526888 & 0.8658153 & 0.95161019 & 0.9751421 & 0.98537864 & 0.993448710 & 0.99858596 & 1.00000000 & $1.000000 \mathrm{e}+00$ & $1.000000 \mathrm{e}+00$ \\
\hline
\end{tabular}




\begin{tabular}{|c|c|c|c|c|c|c|c|c|c|c|}
\hline & PC1 & $\mathrm{PC2}$ & $\mathrm{PC3}$ & PC4 & PC5 & PC6 & PC7 & PC8 & PC9 & PC10 \\
\hline $\begin{array}{l}\text { Standard } \\
\text { Deviation }\end{array}$ & 1.4833993 & 1.3559653 & 0.7905447 & 0.66846109 & 0.46496486 & .27508141 & 0.24430141 & 0.164692634 & 0.12536473 & $1.071725 \mathrm{e}-08$ \\
\hline $\begin{array}{l}\text { Proportion } \\
\text { of Variance }\end{array}$ & 0.3997008 & 0.3339766 & 0.1135198 & 0.08116544 & 0.03926984 & 0.01374489 & 0.01084104 & 0.004926826 & 0.00285476 & $2.086341 \mathrm{e}-17$ \\
\hline $\begin{array}{l}\text { Cumulative } \\
\text { Proportion }\end{array}$ & 0.3997008 & 0.7336774 & 0.8471972 & 0.92836265 & 0.96763249 & 0.98137738 & 0.99221841 & 0.997145240 & 1.00000000 & $1.000000 \mathrm{e}+00$ \\
\hline
\end{tabular}

601

603

604

\begin{tabular}{|c|c|c|c|c|c|c|c|c|c|c|}
\hline & PC1 & PC2 & PC3 & PC4 & PC5 & PC6 & PC7 & PC8 & PC9 & PC10 \\
\hline $\begin{array}{l}\text { Standard } \\
\text { Deviation }\end{array}$ & 0.9521091 & 0.4400194 & 0.4043468 & 0.28925893 & 0.28925893 & 0.26672038 & 0.18464787 & 0.14308542 & 0.1052076 & $4.998999 \mathrm{e}-09$ \\
\hline $\begin{array}{l}\text { Proportion } \\
\text { of Variance }\end{array}$ & 0.5643829 & 0.1205436 & 0.1017908 & 0.07603491 & 0.05209236 & 0.04429073 & 0.02122702 & 0.01274651 & 0.0068912 & $1.555846 \mathrm{e}-17$ \\
\hline $\begin{array}{l}\text { Cumulative } \\
\text { Proportion }\end{array}$ & 0.5643829 & 0.6849265 & 0.7867173 & 0.86275219 & 0.91484454 & 0.95913527 & 0.98036229 & 0.99310880 & 1.0000000 & $1.000000 \mathrm{e}+00$ \\
\hline
\end{tabular}

605

606

607 
612

\begin{tabular}{|c|c|c|c|c|c|c|c|c|c|c|}
\hline & PC1 & PC2 & PC3 & PC4 & PC5 & PC6 & PC7 & PC8 & PC9 & PC10 \\
\hline $\begin{array}{l}\text { Standard } \\
\text { Deviation }\end{array}$ & 0.6883491 & 0.4847523 & 0.4431278 & 0.28439448 & 0.20530257 & 0.12568370 & 0.10428894 & 0.077093756 & 0.056985312 & 0 \\
\hline $\begin{array}{l}\text { Proportion } \\
\text { of Variance }\end{array}$ & 0.4452969 & 0.2208370 & 0.1845398 & 0.07601065 & 0.03961146 & 0.01484534 & 0.01022136 & 0.005585609 & 0.003051814 & 0 \\
\hline $\begin{array}{l}\text { Cumulative } \\
\text { Proportion }\end{array}$ & 0.4452969 & 0.6661340 & 0.8506738 & 0.92668442 & 0.96629588 & 0.98114122 & 0.99136258 & 0.996948186 & 1.000000000 & 1 \\
\hline
\end{tabular}

613

615

616

\begin{tabular}{|l|l|l|l|l|l|l|l|l|l|}
\cline { 2 - 8 } \multicolumn{1}{c|}{} & PC1 & PC2 & PC3 & PC4 & PC5 & PC6 & PC7 & PC10 \\
\hline $\begin{array}{l}\text { Standard } \\
\text { Deviation }\end{array}$ & 0.8330142 & 0.6087193 & 0.29815709 & 0.16671896 & 0.13650615 & 0.101160670 & 0.072834422 & 0.046432140 & 0 \\
\hline $\begin{array}{l}\text { Proportion } \\
\text { of Variance }\end{array}$ & 0.5699614 & 0.3043511 & 0.07301818 & 0.02283025 & 0.01530542 & 0.008405511 & 0.004357266 & 0.001770835 & 0 \\
\hline $\begin{array}{l}\text { Cumulative } \\
\text { Proportion }\end{array}$ & 0.5699614 & 0.8743125 & 0.94733072 & 0.97016097 & 0.98546639 & 0.993871899 & 0.998229165 & 1.000000000 & 1 \\
\hline
\end{tabular}


624

625

627

628

\begin{tabular}{|c|c|c|c|c|c|c|c|c|c|c|}
\hline & PC1 & PC2 & PC3 & PC4 & PC5 & PC6 & PC7 & PC8 & PC9 & PC10 \\
\hline $\begin{array}{l}\text { Standard } \\
\text { Deviation }\end{array}$ & 0.4840696 & 0.3915002 & 0.18868389 & 0.15365391 & 0.13146106 & 0.11715693 & 0.09900876 & 0.08018314 & 0.060174697 & 0.045424239 \\
\hline $\begin{array}{l}\text { Proportion } \\
\text { of Variance }\end{array}$ & 0.4688989 & 0.3067098 & 0.07124153 & 0.04724446 & 0.03458262 & 0.02746627 & 0.01961602 & 0.01286559 & 0.007245885 & 0.004128944 \\
\hline $\begin{array}{l}\text { Cumulative } \\
\text { Proportion }\end{array}$ & 0.4688989 & 0.7756087 & 0.84685022 & 0.89409468 & 0.92867730 & 0.95614356 & 0.97575958 & 0.98862517 & 0.995871056 & 1.000000000 \\
\hline
\end{tabular}

Table S8: Soil log10 PCA output.

\begin{tabular}{|c|c|c|c|c|c|c|c|c|c|c|}
\hline & PC1 & $\mathrm{PC2}$ & $\mathrm{PC3}$ & PC4 & PC5 & PC6 & PC7 & PC8 & PC9 & PC10 \\
\hline $\begin{array}{l}\text { Standard } \\
\text { Deviation }\end{array}$ & 0.7258514 & 0.6128254 & 0.3543896 & 0.29853939 & 0.25765593 & 0.15895068 & 0.11937154 & 0.095021267 & 0.054517218 & 0 \\
\hline $\begin{array}{l}\text { Proportion } \\
\text { of Variance }\end{array}$ & 0.4265952 & 0.3040843 & 0.1016910 & 0.07216454 & 0.05375277 & 0.02045716 & 0.01153778 & 0.007310754 & 0.002406511 & 0 \\
\hline $\begin{array}{l}\text { Cumulative } \\
\text { Proportion }\end{array}$ & 0.4265952 & 0.7306795 & 0.8323705 & 0.90453503 & 0.95828780 & 0.97874496 & 0.99028273 & 0.997593489 & 1.000000000 & 1 \\
\hline
\end{tabular}


